\title{
Konsepsi Abdu Al-Samad Al-Jawi Al-Palimbani tentang Akidah Dalam Kitabnya Hidayatul Al-Salikin
}

\author{
nfn. Mujib
}

Keywords: books study, characterization, Al-Palimbani, Al-Ghazali, theologian

\section{How to Cite:}

Mujib, nfn. Konsepsi Abdu Al-Samad Al-Jawi Al-Palimbani tentang Akidah Dalam Kitabnya Hidayatul Al-Salikin. Berkala Arkeologi, 14(2), 65-67. https://doi.org/10.30883/jba.v14i2.702
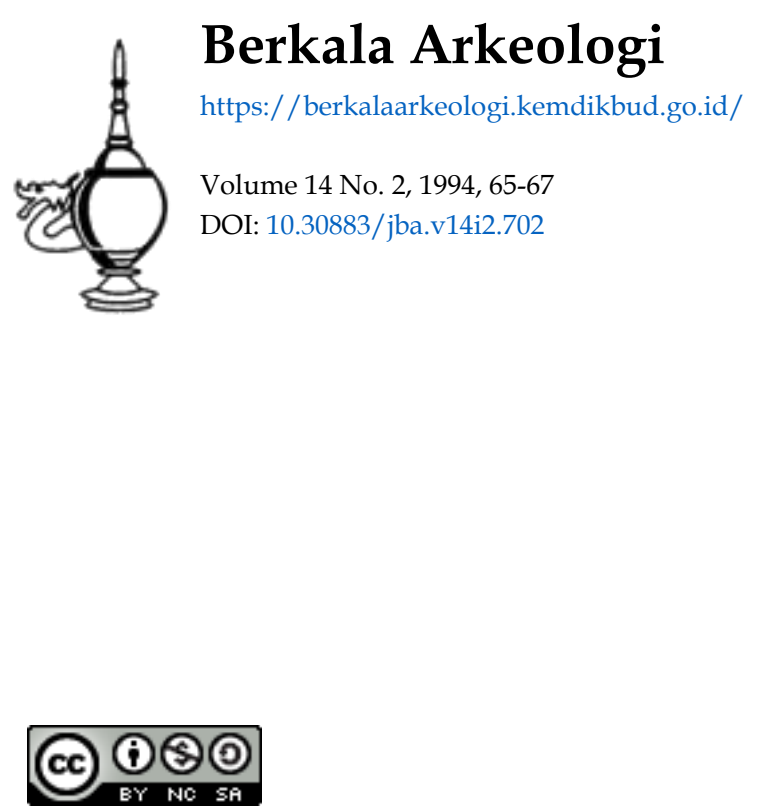

This work is licensed under a Creative Commons Attribution-NonCommercial-ShareAlike $\underline{4.0}$ International License. 


\title{
KONSEPSI ABDU AL-SAMAD ALJAWI AL-PALIMBANI TENTANG AKIDAH DALAM KITABNYA HIDAYATU AL-SALIKIN
}

\author{
Mujib \\ (Balai Arkeologi Palembang)
}

\section{Pendahuluan}

Tulısan ını akan menguraikan tentang konsep-konsep akıdah berdasar telaah dua buah kitab (1) Hidayatu al-Salokin yang merupakan kitab karya terjemahan Al-Palımbani sendiri dari kitab ke (2) Bidayatu al-Hidayah karya A-Ghazali.

Tusisan ıni dımaksudkan akan menjelaskan pada beberapa hal berikut.

1. Penokohan Al-Palimbani sebagai ulama dan penterjemah serta konsep dan pandangannya terhadap Akidah Islamiah yang berani, karena berbeda dengan konsep-konsep akidah yang dikemukakan oleh ulama lain, dalam satu aliran Ahiu al-Sunah wa al-Jama'ah

2. Mengungkap latar belakang penulisan kitab tersebut sehingga jelas permasalahannya, di sampıng kajian-kajian menarik lainnya

Dalam menelaah kitab-kitab tersebut di atas, pertama-tama akan dibaca kitab Hidayatu अ-Salıkın dan Kıtab Bıdayatu al-Hidayah. Kemudian dibandingkan antara kedua-nya tentang kekurangan dan kelebihannya masing-masing. Seianjutkan akan ditafsirkan ıde dan gagasan serta konsep akıdah At-Palımbani

Sejarah, Al-Palimbani dan Kitab Hidayatu al Salikin

Pada abad ke-18 M. Palembang mempu. nyaı satu Kesultanan yang sangat terkenal dalam sejaran Nusantara, yaitu Kesultanan Palembang JarL Al-Salam yang didirikan oleh Sultan Mahmud Badaruddın I pada tahun 1737 M (Djohan 1989 2) Pada waktu kesultanan dipimpın oleh Suitan Muhammad Dahauddin, Palembang menjadi susat syiar Islam dan Sastra Melayu di Nusantara. Hal In d dsebabkan karena beliau sangat memperhatikan kehidupan keagamaan termasuk ulamanya Palembang menjadi pusat ilmu pengetahuan agama Islam karena banyaknya ulama dan banyak didatangi sieh masyarakat pencari ilmu (M. Chatib Quzwain.1985:8). Salah seorang di antaranya adalah Syeikh Abdu al-Samad al-Jaw al-Palimbani. la adalah anak lakı-laki Syeikh Abdu al-Jalil bin Syeikh Abdu al-Wahab bın Syeikh Ahmad al-Mahdarı dari Yaman dan lbu Raden Ranti seorang keturunan ningrat Palembang ( $M$ Cnatıb, Quswain, 1985 9) la dilahırkan pada tahun 1116 H./1704 M. di Palembang. Berkenaan dengan itu, dinısbahkan namanya dengan nama kota kelahırannya, Palembang menjadi AlDalimbanı (A)-Palimbani,1352 H.2) la diperkirakan wafat pada tahun 1788 M. (Djohan, 1988:35) diperkirakan di Haah Yai. dalam wilayah kekuasaan Siam dekat Songkhla (Kedah Utara) ketıka terjadi peperangan antara pasukan Kedah dengan pasukan Siam. Karena itu makamnya tıdak diketemukan (M. Chatib \uzwain, 1985 11)

Masa hidupnya ia sangat rajin belajar se bab itulah ia digelari Rabbanıy (orang yang sangat terpelająr, pandai, dan sangat menguasa ilmu agama). Dalam usıa muda ia dikırim ayahnya belajar ke Mekah untuk belajar. Tetapı di sa na (M. Chatib Quzwain,1985:12) sampai suatu ketika ia belajar ilmu Tasawuf kepada Muhammad As-Saman Al-Madani (wafat 1190 H/1776 M) (M. Chatıb Quzwaın, 1985: 26)

Beberapa kitab yang ditulisnya ada yang berbahasa Arab dan ada yang berbahasa Melayu. Selain itu ada yang merupakan terjemahan atau buah karya pikirannya sendirı. Seluruh kıtab tersebut ditulisnya di Mekah dan telah diterbitkan di berbagai negara, yaitu Mesir, Indıa, Singapura dan Indonesıa (Ahmad bin Muhammad Zein al. Qathanı: 1352 H: 308) Menurut Drewes kitab yang telah ditulis Al-Palimbanı ada tujuh buah dua buah sudah dicetak, empat buah masih da lam bentuk naskah dan sebuah baru dikenal na. manya saja (Drewes, 1977:222-224)

Salah satu karya Al-Palımbani yang dikenal adalah kitab Hidayatu al-Salikin. Judul lengkap kitab ini adalah Hidayatu al-Salikin fi Suluki Maslaki al-Mutaqin (Al-Palimbani, 1352 Hi 3 ;) diterjemahkan menjadi: Petunjuk bagi orangorang yang menempuh Jalan yang Dilalui oleh orang-orang yang bertaqwa. Kitab inı merupakan terjemahan kıtab Bidayatu al-Hidayahnya $\mathrm{Al}$ Ghazali seorang tokoh sufi yang sangat berpengaruh tulisan yang dipakai adalah tulisan Arab berbahasa Jawi (Melayu) (Ai-Palimbani, 1352 H:3

Judui tersebut dapat diduga bahwa kitab tersebut merupakan kitab yang berisikan petun juk untuk bertaqwa dengan konotası sufi $D$ i da

1 Kata 'Rabbaniy' sebenamya berarti orang-orang yang pandal dan amat memahamı tentang agama Di dalam agama Masehi gelar ini diberikan kepada pemimpin pendeta. sebab mereka dianggap sangat memahamı tentang agamanya Di irar. kata Rabbaniy sebagal gelar orang yang sangat memahami agama tidak dapat kita temukan sebat. mereka biasa memben gelar kepada orang yang sangat pandai dalam agama dengan 'Mullah' (LIna: Loui Ma'luf. dalam Munjıd. 243 
lamnya bukan saja terdiri dari terjemahan kitab Bıdayatu Al-Hidayah, melainkan terdiri dari pandangan pribadi Al-Palimbani yang merupakan hasil kajian terhadap beberapa kitab yang dikarang ulama lain. Hal tersebut tidak terlihat jelas apabila tidak diperiksa kitab yang diterjemahkannya dan hasil terjemahannya. Kajian katib tersebut dapat disimpulkan bahwa konsepsi akidah itu adalah merupakan pandangannya ( $\mathrm{Bab} \mathrm{l}$ ).

Ahmad bın Muhammad Zeinu al-Qatani, pentashih (editor) kitab ini mengomentari bahwa kitab ini adalah kitab berbahasa melayu yang pertama kalı dicetak dan diterbitkan di Mesir dengap tulisan tangan Hadrat al-Syalkh Hasan al-Tuhi. ${ }^{2}$ Pencetakan itu berhasil karena budi baik prakarsa dan tanggungan yang diberikan oleh $\mathrm{Ha}$ drat al-Amjad al-Kasymiri serta harapan dan pertimbangan Abdu al-Shani, anaknya. Maka dapat difahamı jika dalam kitab terbitan Mesir ini terdapat beberapa salah cetak dan terbaliknya penulisan angka, lafal, dan tanda bacanya (Ahmad bın Muhammad Zeınu asl-Qatani, 1352: 308).

Terjemahan kitab Hidayatu al-Salikin yang berbahasa Jawi (melayu) dari kitab Bidayatu alHidayah yang berbahasa Arab ini adalah merupakan langkah berani Al-Palimbani, mengingat para ulama generasi sesudahnya jarang yang melakukannya. Penerjemahan yang selama ini diakukan hanya sebatas pemberian syarah (urasan keterangan) dengan bahasa asal kitab yang disyarahinya Hal tersebut tampak seperti yang dilakukan oleh Syeikh Nawawi al-Jawi al-Banteni dalam menyarahı kitab Bidayatu al-Hidayah, kitab yang juga diterjemahkan oleh Al-Palimbani (Nawawı, $1289 \mathrm{H}: 101$ )

Penulisan kitab ini dilatarbelakangi oleh kondisi masyarakat Palembang dan sekitarnya. Masyarakat masa itu walaupun telah lama mengenal dan memeluk Islam (awal abad kө-16), (Graff dan Pigeaud, 1974 :249) namun mereka sampal abad ke-19 belum banyak memahami Isiam kecuali mereka yang diperkotaan (Thomas Arnold, 1986:324). Menyadari hal itu, Al-Palimbanı sebagai seorang ulama dan merasa bertanggung Jawab untuk memberikan bimbıngan kepada mereka tentang islam, maka dituliskannya kitab-kitab dengan bahasa melayu, bahasa keseharian mereka agar mereka dapat menyerap ajarannya itu dengan mudah.

Di samping itu, sebelum Al-Palimbani pulang ke Palembang dari Mekah, di kota itu telah kemasukan ajaran Wihadu al-Wujud, suatu faham sufi yang percaya bahwa segala sesuatu itu Tuhan. Alaran tersebut mengakui bahwa Tuhan dan dunia manunggal, demikian pendapat Lalan-

\footnotetext{
2 Hadrat al-Syaikh Hasan al-Tuhı terkenal tulisan tanganrrya di masjio- masjid Jami juga ALAzri har Kairo
}

de yang dikutib oleh P.J. Zoet-mulder (1990:2) Hal tersebut menimbulkan polemik terbuka dengan faham tasawuf Al-Ghazali (Djohan, 1989: 117). Berdasarkan kenyataan tersebut maka ditulislah kitab-kitab yang dapat mendukung faham Al-Ghazali, seperti kitab Hidayatu al-Salikin

Tujuan penterjemahan kitab dengan bahasa Melayu tersebut semata-mata untuk diambıl manfaatnya oleh orang yang tidak memahami bahasa Arab, namun memahami bahasa Melayu (Al-Palimbani, 1352:3)

\section{Konsepsi Akidah Al-Palimbani}

Konsepsi akidah Al.Palimbanı tertuang da lam Bab I kitab Hidayatu al-Salikin. Pada bab in Al-Palimbani sengaja tidak menterjemahkan naskah asli kitab Bidayatu al-Hıdayahnya Al-Ghazal karena bab in tidak terdapat kitab tersebut, me. lainkan ia mengutarakan ide dan gagasan sendir। dengan merangkum data tentang akidah darı be berapa ulama lain, kemudian merangkumnya dalam suatu konsep akıdah. Konsepsı akıdah tersebut adalah konsep akidah Ahiu al-Sunah wa alJama'ah, yang diungkapkan melalui metode dan teknik yang tidak lazım digunakan oleh uiama lain dari kalangan Ahlu al-Sunah wa al- Jama'ah

Pokok-pokok konseposi akidah Al-Palımba ni adalah sebagai berikut.

1. Menerangkan eksistensi Allah dan jatı dırı-Nya

2. Menerangkan sifat-sifat Allah dan sifat-sifat para rasul.

3. Menerangkan kewajiban orang mukalaf (orang yang telah terkena kewajiban hukum Allah) yang aqil (berakal) dan baligh (telah sampal usia dewasa), percaya bahwa Allah mengutus seorang rasul/nabi terakhir. Muhammad saw

4. Menerangkan kewajiban mukalaf yang aqıl dan baligh untuk membenarkan apa yang dikabarkan Muhammad, baik khabar mengenaı kehıdupan dunia maupun khabar mengena keh: dupan sesudah mati, seperti

a. Adanya dua orang malaıkat yang bernama Mungkar dan Nakır, yang menanyai orang mati di alam kubur tentang. siapa Tuhanmu, siapa nabımu, apa agamamu, dsb

b. Adanya siksa kubur

c. Adanya mizan (timbangan di akhırat)

d. Adanya sırat (titian dı akhırat)

e. Adanya telaga Al-Kautsar

f. Adanya Hisab (perhitungan amal balk dan buruk manusı)

g. Adanya semua mu'min akan dikeluarkan dari api neraka

h Adanya syafa'at segala nabi dan syunada

5. Menerangkan kewajıban orang mukaiaf yang aqil dan baligh untuk meyakini bahwa para sa habat nabi itu adil

Darı sekian banyak konsepsı akıdah Al-Palimbanı yang paling menarık adalah uraıan ten- 
tang buktı adanya (eksıstensi) Allah, kemudian kalimat Tauhid dan kalimat rasul serta uraian sifat-sifat Allah dan para rasul.

Di dalam menerangkan sifat-sifat para rasul, Al-Palimbani mengatakan bahwa para rasul itu mempunyaı 3 sıfat wajib yaitu Sidik (benar), Amanah (dapat dipercaya) dan Tabligh (menyampaikan amanat). la tidak menyebutkan sifat keempat sepertı yang diungkapkan oleh Ahlu al-Su. nan wa al-Jama'ah yang laın, yaitu Fathanah (pandal cerdik) Inilah yang berbeda dengan konsep yang lain. Kemudian para rasul mempunyal sifat-sifat yang berlawanan dengan sifat wajib, yaitu sifat-sifat Mustahil (tidak mungkin ada) $K, d z b$ (dusta), Khiyanat (khiyanat, tidak dapat dipercaya) dan Kitman (menyembunyikan amanat).

\section{Analisis}

Teknik penterjemahan yang dipakai Al-Palımbanı, disampıng masih mempergunakan bahasa Melayu lama, terjemahan bebas, juga masih mempergunakan teknik terjemahan harfiyah (letterlıjk) bukan terjemahan tafsiriyah (interpretatif). Inı tampak pada setiap ungkapan terjemahannya. Hal tersebut dapat dicontohkan terjemahan kalimat Kana qabla an xalaqa al-zamana wa al-makana wa huwa al-ana 'ala ma huwa kana, sebagal 'Adalah Allah ta'ala itu dahulu darı pada bahwa menjadikan akan zaman dan tempat dan adalah Allah ta'ala sekarang atasnya yaitu atas do dan atas tiada la sedia tiada berubah-ubah ${ }^{\circ}$ Artı kalımat dı atas sebenarnya diterjemahkan sebagar berikut "Sebelum Allah ta'ala menjadikan waktu dan tempat. seperti sekarag ini la tetap sepertı apa adanya, tidak pernah berubah" Hal tersebut terjadi karena kehati-hatiannya agar tıdak meienceng dari teks asal.

3 inı odak lazım Jiusarakan oleh ulama aliran Ahiu atSunah wo at-Jama'ah. Periksa Syah-menan Zaenı dalam buku Isi Pokok kandungan Ał-Qur'an, 42)

4 Di dalam ALQur’an tudak ddapati satu kata pun yang menyebutkan Fathanah. Sedang kata Si-dik, dapat dilihat pada surat Al-Arzab, ayat 22. Yasin, ayat 52 dan ALFath ayat 27. Kata i ab-ligh dapat kita dapat pada surat A-Maidah ayat 79. ALArzab ayat 39. Al A'raf ayat 79 dan Hud ayat 57 . Semuanya bertalian dengan sifat para rasul

5 Wingtedt menyebutkan hal itu pada bukunya: The Malay-A Cultur History. London, 196142

6 W.M. Thackston. pengajar Bahasa Arab pada Harvard University tidak pemah mentejeman-kan Kana dengan Adalah, Ina dengan Sesung-guhnya. Periksa An Introduction to Koranic Arabic. Harvard University. him. 18
Metode pembahasan yang dipakai dalam konsepsi Al-Palimbanı adalah metode Isimbatiyah. Metode tersebut diambil dari inti ajaran se. seorang, namun diakunya sebagai pendapatnya Hal ini tampak pada pembahasannya tentang kalimat 'La ilaha illa al-lah Muhammadu al-rasuiullah'. Sebenarnya la banyak diilhami oleh gaya pemikiran Al-Ghazali yang menempatkan kalımat tersebut sebagai inti ajaran akidah islamiyah

la juga mempergunakan kata-kata "bermula dengan ... dan khitabnya (sasaran yang diajaknya bicara) adalah "sekalian orang mukalaf yang akil baligh" baru menuturkan apa yang ia jadıkan ajarannya (Al-Palimbani, 1352 H :17). Kalimat ia llaha illa allah Muhammadu al-rasulullah sebe. narnya dimaksudkan untuk menerangkan betapa pentingnya kalimat tersebut untuk diyakinı oleh mereka orang-orang yang telah akil dan balikh. la tıdak mengenyampingkan pentingnya rukun imam yang enam (percaya kepada Allah) tetapı dalam tasawuf yang digelutinya, hal yang sangat esensial adalah: meyakini dengan seyakin-yakınnya bahwa "tıada Tuhan selaın Allah dan Mu. hammad itu utusan Allah" Hal itu la sebut sebagai "fardlu 'ain" (Al-Palimbani: 1352 H 7) Pada masalah lain disebutkan sebagal 'Fardlu kıfayah' seperti yang dikemukakannya dalam mukadimah kitabnya "adapun kadar fardlu 'ain pada ilmu tauhid itu maka yaitu mengetahui kadar yang megetahui dengan dia dzat Allah ta'ala dan sifat-Nya yang salbiyah dan sifat-sifat-Nya yang tsubutiyah dengan sekira-kira yang mengesahkan akan iman yakni mengenal barang yang wajib bagi Allah ta'ala dan yang mustahil bagi-Nya dan ayang jaiz. Demikıan lagi mengenai akan seumpama yang demikian itu bagi segala rasul dan beriman dengan segala yang didatangkan oleh mereka itu". Uraian tersebut dapat diketahui adanya tiga pokok masalah yang harus diketahu oleh manusıa mukalaf yaitu: Aliah dan para rasu dengan ajaran-ajaran yang dibawanya, baık menyangkut kehidupan dunia maupun ajaran yang menggambarkan kehidupan akhirat setelah manusia mati nanti. Itulah ajaran asasiah daiam is lam. Sedangkan rukun iman yang enam (percaya kepada Allah, malaikat, kitab-kitab, para rasul harı akhir dan ketentuan akhir Allah), adalah me rupakan penjabaran dari ketıga pokok tersebut

Mengenai sifat-sifat Allah yang tiga (wajib mustahıl serta jaiz) juga diuraikan secara rıncı oleh Al-Palimbanı, yaıtu Allah mempunyaı sıfat wajib 20 , sifat mustahil 20 karena sifat inı merupakan kebalikan sifat wajib, dan 1 sifat jaız Uraian inı sesuai dengan konsepsı akidah Ahu alSunah wa al-Jama'ah. Dalam menjelaskan sifat-

7 Lihat Louis Ma'luf dalam ktabnya. A-Munıld. hlm 786 
sifat para rasul, Al-Palımbanı mengungkapkan hal yang tidak lazım diuraikan oleh ulama Ahu alSunah wa al-Jama'ah. Hal tersebut adalah dikemukakannya sifat wajib bagi rasul ada 3 (Sidik, Amanah dan Tabligh), sifat mustahil ada 3 (Kıdzb, Khiyanat dan Kitman). la tidak menyebutkan sıfat keempat sebagaimana ulama lain menyebutkannya, yaitu fatanah (dalam sıfat wajib) dan baladah (daiam sifat mustahil). Kemungkinan Al-Palimbani berpendapat bahwa para rasul tidak mengetahui apapun kecuali yang diberikan oleh Allah swt. walaupun kenyataannya para rasul itu fatanah (pandai dan cerdik) sehingga mereka dipilih Allah menjadi rasul. Selain itu kata fatanah, tIdak pernah disebut dalam Al-Qur'an

Tentang kewajiban orang mukalaf yang akil dan baligh untuk mempercayai apa saja yang dibawa oleh Muhammad, semua ulama sepakat, bahwa itu akan terjadi.

\section{Penutup}

Al-Palimbanı telah merubah situası Palembang menjadi sebuah pusat gerakan dan da'wah Islam serta menjadi pusat kesusasteraan Melayu di Nusantara. Hal itu dikarenakan perannya di kancah perjuangan pengembangan ilmu pengetanuan dan agama. Pandangàn dan konsepsinya tentang Islam telah menjadikan rakyat Palembang cınta akan $॥ \mathrm{mu}$

Al-Palimbanı adalah seorang tokoh sufi dari kalangan Ahlu al-Sunah wa al-Jama'ah. Kitab Hidayatu al-Salıkın adalah salah satu bukti bahwa la adalah penganut sufi. Kitab ini diterjemahkan dalam kitab karya A)-Ghazali, Bidayatu alHidayah. Konsepsınya tentang akıdah dituangkan melalui pokok-pokok pikirannya bahwa seluruh mukalaf harus mempercayar eksıstensi Allah dengan segala sıfat-sifat-Nya, kerasulan Muhammad dan berita yang dibawanya. Dalam hal sifat wajıb bagi Rasul, Al-Palimbani berbeda dengan ulama sealirannya. Begitu juga dalam sistem pemaparannya. Kitab-kitab karangan Al-Palimbani masih banyak yang belum ditelaah dengan baik dan intensif oieh generasi masa kini. Untuk itu perlu upaya menelusuri naskah-naskah yang pernah ditulisnya untuk ditelaah agar kita lebih memahamı ajaran-ajarannya.

\section{KEPUSTAKAAN}

\section{Al-Qur'an Al-Karim}

Abdul Bagi, Muhammad Fuad, 1987, Al-Mu'jamu a)-Mufahras, Beirut

Ai-Palimbanı, Syeikh Abdu al-Samadal-Jawl, $1.352 \mathrm{H}$. Hidayatu al-Salikin, Bombay
Al-Tharabalisı, 1967. Al-Hu unu al-Hamidiyah, Surabaya.

Arnold,Thomas W. 1985, Sejarah Da'wah Islam, terjemahan, Jakarta.

Ai-Sya'rawi,Muhammad Mutawalli, 1976, Al-Muktarmin Tafsiri al-Quran, Carro.

Al-Sya'rawi, Muhammad Mutawalli. 1986, Min Faidli al-Rahman fi Tarblyati al-Insan, Cairo

Djohan Hanafiah, 1988, Masjid Agung Palembang, Jakarta.

1989, Kuto Besak, Jakarta.

Drewes,G.W.J.1977. Direction For Travellers On The Mystic Path, The Hague

Graff, H.J.de.,1989. Kerajaaan-kerajaan Islam di Jawa, terjemahan, Jakarta

Ma'luf, Louis, 1986, Al-Munjid, Beirut

Muhammad Abduh, 1976. Risalatu al-Tauhıd Cairo.

Nawawi,Muhammad, $t t$, Muraqi al-'Ubudiyah Semarang

Thacston Jr., tt, An Introduction to Koranic Arabic, Harvard University

Winstedt,R O.,1961, The Malay - A Cultural History, London.

Zoetmulder,P.J.,1990. Manunggaling Kawulo Gusti, terjemahan, Jakarta

Zaeni, Syahmenan, 1986, Isi Pokok Kandungan Al-Qur'an, Surabaya

Quzwain,M.Chatib, 1985. Mengenal Allah, Jakarta

Al-Ghazali, tt, Bidayatu al-Hidayah, Semarang 